\title{
Genomic analysis for heat and combined heat-drought resilience in bread wheat under field conditions
}

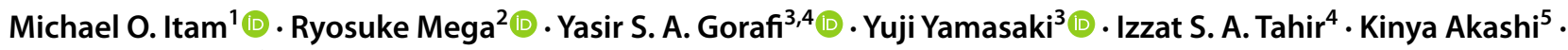 \\ Hisashi Tsujimoto ${ }^{3}$ (1)
}

Received: 1 June 2021 / Accepted: 6 October 2021 / Published online: 16 October 2021

(c) The Author(s) 2021

\begin{abstract}
Key message GWAS on a bread wheat panel with high D genome diversity identified novel alleles and QTLs associated with resilience to combined heat and drought stress under natural field conditions.

Abstract As heat $(\mathrm{H})$ and drought stresses occur concurrently under field conditions, studying them separately offers limited opportunities for wheat improvement. Here, a wheat diversity panel containing Aegilops tauschii introgressions was evaluated under $\mathrm{H}$ and combined heat-drought (HD) stresses to identify quantitative trait loci (QTLs) associated with resilience to the stresses, and to assess the practicability of harnessing Ae. tauschii diversity for breeding for combined stress resilience. Using genome-wide analysis, we identified alleles and QTLs on chromosomes 3D, 5D, and 7A controlling grain yield (GY), kernel number per spike, and thousand-kernel weight, and on 3D (521-549 Mbp) controlling GY alone. A strong marker-trait association (MTA) for GY stability on chromosome 3D (508.3 Mbp) explained $20.3 \%$ of the variation. Leaf traits-canopy temperature, vegetation index, and carbon isotope composition-were controlled by five QTLs on 2D (23-96, 511-554, and 606-614 Mbp), 3D (155-171 Mbp), and 5D (407-413 Mbp); some of them were pleiotropic for GY and yield-related traits. Further analysis revealed candidate genes, including GA20ox, regulating GY stability, and CaaX prenyl protease 2, regulating canopy temperature at the flowering stage, under $\mathrm{H}$ and $\mathrm{HD}$ stresses. As genome-wide association studies under $\mathrm{HD}$ in field conditions are scarce, our results provide genomic landmarks for wheat breeding to improve adaptation to $\mathrm{H}$ and HD conditions under climate change.
\end{abstract}

\section{Introduction}

In many wheat-growing regions, heatwaves and drought episodes occur concurrently and are considered the most damaging climatic stressors for wheat (Zampieri et al. 2017). In

Communicated by Peter Langridge.

Hisashi Tsujimoto

tsujim@tottori-u.ac.jp

1 Arid Land Research Center, Tottori University, Tottori 680-0001, Japan

2 Graduate School of Sciences and Technology for Innovation, Yamaguchi University, Yamaguchi 753-8515, Japan

3 Arid Land Research Center, Tottori University, Tottori 680-0001, Japan

4 Agricultural Research Corporation, Wheat Research Program, P.O. Box 126, Wad Medani, Sudan

5 Faculty of Agriculture, Tottori University, Tottori 680-8553, Japan the current climate change scenario, every $1{ }^{\circ} \mathrm{C}$ rise in global mean temperature results in a $6 \%$ reduction in wheat yield, and a $17 \%$ increase in agricultural water supply is needed to prevent drought stress (Pennisi 2008; Zhao et al. 2017). This implies that global wheat production will continue to be lower than demand, especially as global population increases (Food and Agriculture Organization of the United Nations 2020). In semiarid regions, where heatwaves and drought episodes are common, an annual grain yield (GY) increase of up to $2.7 \%$ is needed (Iizumi et al. 2021). Such an increase may be difficult to achieve using the current elite germplasm, which has a narrow gene pool (Ogbonnaya et al. 2013). Therefore, the use of new genetic resources has the potential to facilitate wheat breeding for resilience to combined stresses (Reynolds et al. 2015).

Wheat wild relatives are a good source for developing new genetic materials; one such relative is Aegilops tauschii, the $\mathrm{D}$ genome progenitor of bread wheat (Tsujimoto et al. 2015). A wheat multiple synthetic derivative (MSD) population was developed using 43 Ae. tauschii accessions as 
a platform to explore the genetic diversity of Ae. tauschii for wheat improvement (Tsujimoto et al. 2015; Gorafi et al. 2018). This population exhibited high genetic diversity when characterized under heat $(\mathrm{H})$ stress in Sudan (Elbashir et al. 2017). Under drought stress in Japan, some MSD lines showed better adaptation than their backcross parent and check cultivars (Itam et al. 2020a, 2021). However, the genetic basis of the diversity in resilience to $\mathrm{H}$, drought, and combined heat-drought (HD) stress has not been fully explored. Moreover, reports on genome-wide association studies (GWAS) for HD in bread wheat under natural field conditions are scarce. Qaseem et al. (2019) and Schmidt et al. (2020) reported shared genomic regions across different conditions, including HD stress, in wheat cultivars and landraces grown in polytunnels. A few other GWAS conducted under similar or more controlled environments have been extensively reviewed (Tricker et al. 2018). However, results from controlled environments may not be replicated in natural field conditions, and information from field conditions is needed to apply the findings to practical breeding.

The objective of this study was to identify QTLs associated with $\mathrm{H}$ and $\mathrm{HD}$ stress resilience in bread wheat under field conditions and to assess the practicability of harnessing Ae. tauschii diversity for combined stress resilience breeding. We evaluated a systematically selected wheat diversity panel (consisting of 145 MSD lines) under H and HD in Wad Medani, Sudan, in 2019 and 2020, and identified novel alleles and QTLs for several traits, including GY and related traits. The loci for most leaf traits, including canopy temperature and normalized difference vegetation index (NDVI), were pleiotropic for GY and related traits. The identified candidate genes suggest the role of gibberellin homeostasis in maintaining GY stability and of CaaX prenylation in regulating canopy temperature under the combined stress. Our study provides new genetic materials and QTLs for breeding wheat with improved resilience to $\mathrm{H}$ and $\mathrm{HD}$ conditions.

\section{Materials and methods}

\section{Plant materials}

A diversity panel of 145 MSD lines and 5 check cultivars was used (Table S1). The study was originally designed with 155 MSD lines and 5 check cultivars, but 10 MSD lines did not flower due to vernalization requirement and were excluded. The 145 lines used are a subset of 400 MSD lines characterized for $\mathrm{H}$ tolerance in Sudan (Elbashir et al. 2017). The MSD panel contained introgressions from 37 accessions of Ae. tauschii (DD genome) and the durum wheat cultivar 'Langdon' (AABB genome) (Matsuoka and Nasuda 2004). The Ae. tauschii accessions used were originally collected from HD stress-prone areas in the Middle East and Central
Asia, including China and the Caucasus. The resulting synthetic hexaploid lines (AABBDD) were crossed with the Japanese bread wheat cultivar 'Norin 61' (hereafter N61, AABBDD). To reduce linkage drag, the $\mathrm{F}_{1}$ hybrids were backcrossed to N61 (Tsujimoto et al. 2015). Therefore, the A and B genomes of the MSD lines are biparental (from 'Langdon' and N61), whereas the D genome is multiparental (from 37 Ae. tauschii accessions and N61). The lines in the diversity panel were selected based on similar days to $50 \%$ heading (DH) and were evaluated under $\mathrm{H}$ and HD stress in Sudan during the 2018-19 ( $\mathrm{BC}_{1} \mathrm{~F}_{6}$ generation) and 2019-20 $\left(\mathrm{BC}_{1} \mathrm{~F}_{7}\right.$ generation) growing seasons (hereafter 2019 and 2020 seasons, respectively).

\section{Experimental site and design}

All experiments were conducted at the Gezira Research Farm, Agricultural Research Corporation, Wad Medani, Sudan $\left(14^{\circ} 24^{\prime} \mathrm{N}, 33^{\circ} 29^{\prime} \mathrm{E}, 407 \mathrm{~m}\right.$ above the sea level). The Gezira Research Farm is a dry, hot irrigated field categorized in mega-environment 5 for wheat cultivation (Gbegbelegbe et al. 2017). It has a heavy clay soil ( $\mathrm{pH} \mathrm{8.0-8.4)} \mathrm{with} \mathrm{low}$ contents of organic matter $(<5 \%)$, nitrogen, and phosphorus (Elbashir et al. 2017). Each experiment was designed in an alpha lattice with two replications. A total of 8 blocks per replication with 20 plots per block were used. Each plot had four rows, $1 \mathrm{~m}$ long and $0.2 \mathrm{~m}$ apart.

\section{Field management and drought treatment}

Seeds were treated with the insecticide Gaucho (imidacloprid, 35\% WP, Bayer Crop Science, Kansas City, MO, USA) at $0.75 \mathrm{~g} \mathrm{~kg}^{-1}$ seed to control insect pests. The treated seeds were manually sown at $120 \mathrm{~kg} \mathrm{ha}^{-1}$ during the last week of November. Field management and drought treatment were as described in Elhadi et al. (2021). Before sowing, phosphorus was applied as superphosphate by furrow placement at a rate of $43 \mathrm{~kg} \mathrm{ha}^{-1}$ of $\mathrm{P}_{2} \mathrm{O}_{5}$. Irrigation was applied every 10-12 days, and the plots were hand-weeded at least twice. Soil water potential was monitored every $2 \mathrm{~h}$ by sensors (Decagon Devices, Pullman, WA, USA) buried $20 \mathrm{~cm}$ in the soil. To create the HD condition, drought was imposed by withholding irrigation when $50 \%$ of all genotypes had reached flowering, while regular irrigation continued under the $\mathrm{H}$ condition. To avoid permanent wilting, plots under the HD condition were re-watered when the soil water potential approached - $900 \mathrm{kPa}$ (Fig. 1). In Wad Medani, Sudan, there is no rain during the winter season and the relative humidity is generally low (Elsheikh et al. 2015). We obtained relative humidity data from January to March 2020, and the daytime value was between 20 and $30 \%$. The air temperature and relative humidity of the field were obtained from the Sudan 
Fig. 1 Field conditions. a, b Daily air temperature in a 2019 and b 2020. c, d Soil water potential in heat and combined heat-drought conditions in $\mathbf{c}$ 2019 and d 2020. The dotted arrows indicate the time points when the three canopy temperature measurements (CT1, CT2, and CT3) were taken a

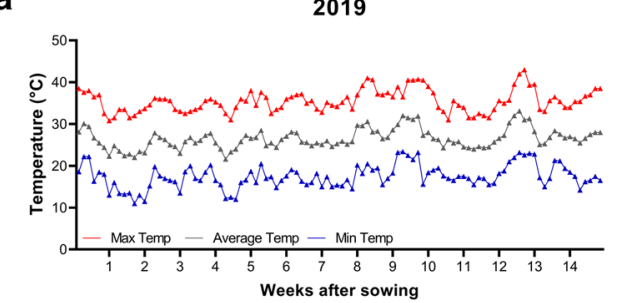

C

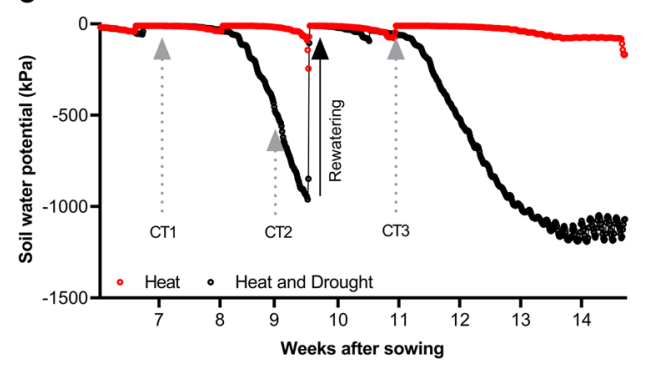

b

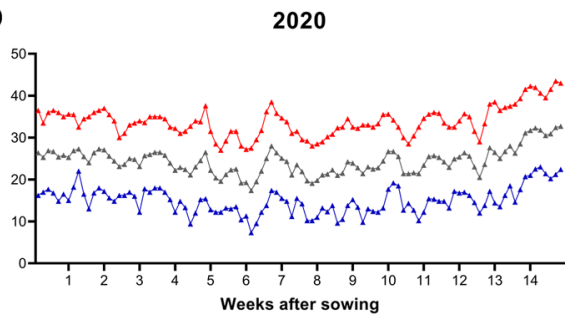

d

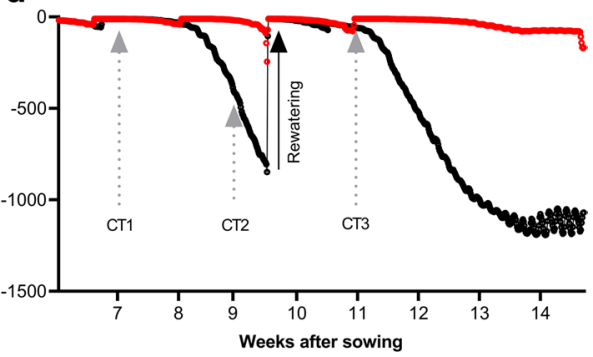

Meteorological Agency and from a weather station within the field.

\section{Evaluated traits}

\section{Morphophysiological traits}

Morphophysiological traits were measured according to Pask et al. (2012). Chlorophyll content (SPAD), ground cover (GC), and NDVI were measured during the grain-filling stage. The SPAD readings were taken from the center of three randomly selected flag leaves per plot using the Minolta SPAD-502 chlorophyll meter (Konica-Minolta, Japan). The GC was estimated using a visual scale of 0-10, with 0 corresponding to $0 \%$ cover and 10 to $100 \%$ cover. NDVI was measured from plant canopy using a handheld optical sensor (GreenSeeker, Trimble Inc., Sunnyvale, CA, USA), and the measurements were taken $50 \mathrm{~cm}$ above the middle of each plot. Canopy temperature (CT) was measured three times: at 7 days before flowering (CT1), during flowering (CT2), and during grain filling (CT3). The CT readings were taken from the canopy of each plot on clear, calm afternoons (between 13:00 and 14:00) using a handheld infrared thermometer (Everest Interscience, Tucson, AZ, USA). The thermometer was angled with the field of view avoiding any bare soil between rows. Plant height $(\mathrm{PH})$, biomass (BIO), number of spikes per plot ( $\mathrm{SN}$ ), number of kernels per spike (KPS), GY, thousand-kernel weight (TKW), and harvest index (HI) were determined at maturity. $\mathrm{PH}$ was measured from the soil surface to the top of the spikes excluding awns. BIO was measured as above-ground dry weight per plot. Ten randomly sampled spikes were used to estimate KPS. GY was determined as grain weight per plot. TKW was determined from the weight of 200 randomly sampled grains. The DH was recorded when $50 \%$ of the spikes in a plot had headed. The days to physiological maturity (DM) was recorded when $50 \%$ of the spikes in a plot showed total loss of green color, while the number of days from heading to maturity was recorded as grain-filling duration (GFD).

\section{${ }^{13} \mathrm{C}$ isotope $\left(\delta^{13} \mathrm{C}\right)$ analysis}

The ${ }^{13} \mathrm{C}$ composition of flag leaves was analyzed using an elemental analyzer connected to a continuous-flow isotope ratio mass spectrometer (EA/IRMS; Thermo Fisher Scientific) as described in Itam et al. (2020b). The analysis was conducted in the laboratory of Arid Land Research Center, Tottori University, Japan. Dry flag leaf samples were collected from three or more randomly selected plants per plot. The flag leaf samples $(1 \mathrm{mg}$ ) were put into tin capsules ( $5 \mathrm{~mm} \times 9 \mathrm{~mm}$, Lüdi Swiss, Switzerland) and entered into a combustion oven by an autosampler. Each sample was measured against $\mathrm{CO}_{2}$ calibrated with an isotope standard to an accuracy of $\pm 0.066 \%$ SD. Finally, the ${ }^{13} \mathrm{C}$ composition was calculated as $\delta^{13} \mathrm{C}=\left[\left(R_{\text {sample }} / R_{\text {standard }}\right)-1\right] \times 1000$, where $R$ is the ${ }^{13} \mathrm{C} /{ }^{12} \mathrm{C}$ isotope ratio.

\section{Genotyping-by-sequencing for association mapping}

Total genomic DNA was extracted from leaves using the CTAB method (Saghai-Maroof et al. 1984), and DNA samples $\left(20 \mu \mathrm{l}\right.$; 50-100 ng $\left.\mu^{-1}\right)$ were sent to Diversity Arrays Technology (DArT) Pty. Ltd., Australia (http://www.diver sityarrays.com) for whole-genome scanning using DArT-seq markers. Complexity was reduced using a combination of restriction enzymes to obtain a subset of restriction fragments for each sample (Sansaloni et al. 2011). The restriction fragments were then sequenced and aligned to the wheat_Chrom_Wheat_Norin61_v1.1 reference genome. 
The nucleotide polymorphisms (referred to as SNP markers) present in the restriction fragments were used for GWAS. The SNP markers are codominant in nature and were scored "0" (homozygous reference allele), " 1 " (homozygous SNP allele), or " 2 " (heterozygote). The markers were filtered on the basis of minimum reproducibility (95\%), call rate (95\%), and average read depth. A total of 14,382 SNP markers were used for association mapping. The $\mathrm{A}, \mathrm{B}$, and $\mathrm{D}$ genomes contain 5965 (41.4\%), 6074 (42\%), and 2343 (16.2\%) markers, respectively.

\section{Statistical analysis}

Best linear unbiased estimates (BLUEs) were obtained for each trait under $\mathrm{H}$ and $\mathrm{HD}$ using the residual maximum likelihood method implemented in META-R (Alvarado et al. 2020). In BLUEs, genotypes and environments were considered as fixed factors, while replication and block were random factors. To minimize the possible confounding effect of heading date, another set of BLUEs (adjusted BLUEs) was calculated by using DH as a covariate (Sukumaran et al. 2018). To separate drought response (DR) from $\mathrm{H}$ response in the HD condition, we divided the predicted means under $\mathrm{HD}$ by those under $\mathrm{H}$ for all traits except days to heading (Schmidt et al. 2020). Analysis of variance was performed for all evaluated traits in GenStat 19th edition (http://www. genstat.co.uk). Broad-sense heritability was estimated for each trait in Plant Breeding Tools v. 1.3 (http://bbi.irri.org). To assess genotype stability across different conditions, GY stability index was calculated using the Finlay-Wilkinson regression model: $y_{i j}=\mu+G_{i}+\beta_{i} E_{j}+\varepsilon_{i j}$, where the regressand $y_{i j}$ is the mean GY of the genotype, the intercept $\mu+G_{i}$ corresponds to the genetic main effect, the slope $\beta_{i}$ corresponds to genotype variability in GY across environments (i.e., GY stability index), the regressor $E_{j}$ is the populationwide variability in GY across environments (i.e., environmental index), and $\varepsilon_{i j}$ is the error term (Finlay and Wilkinson 1963).

\section{Genome-wide association study and candidate gene analysis}

Genome-wide association analysis was performed with both adjusted and unadjusted BLUEs for H, HD, and DR in 2019 and 2020, using the generalized linear model and mixed linear model implemented in TASSEL v. 5 (Bradbury et al. 2007). The generalized linear model was fitted with the first five principal components, whereas the mixed linear model was fitted with the principal components and the Centered_ IBS kinship matrix (Yu et al. 2006). The best-fit model for each dataset was selected using quantile-quantile plots. Significant marker-trait associations (MTAs) were determined at a threshold of $-\log (p)=3$, and the quantile-quantile and Manhattan plots were generated in the R package "qqman" (Turner 2018). Then, the $p$-values were adjusted for multiple testing using false discovery rate (FDR) (Benjamini and Hochberg 1995) at the 0.05 and 0.2 thresholds. To better explore the contribution of the Ae. tauschii $\mathrm{D}$ genome, we also conducted a $\mathrm{D}$ genome-wide analysis using only the $\mathrm{D}$ genome markers. Because the A and B genomes in this panel are biparental, whereas the $\mathrm{D}$ genome is multiparental, conducting an additional GWAS on the D genome increased the statistical power of the analysis. The same analysis method was used for both GWAS. Stable MTAs were found in two or more conditions, and pleiotropic MTAs were found for two or more traits.

The linkage disequilibrium (LD) of the markers was calculated from observed and expected allele frequencies using TASSEL. To determine a critical point beyond which LD is due to true genetic linkage, $r^{2}$ values of the unlinked markers (markers on different chromosomes) were explored. These values were square root transformed, and their 95th percentile was taken as the critical point. Polynomial regressionbased curves were fitted on scatter plots of $\mathrm{r}^{2}$ against marker distance, and the critical $\mathrm{r}^{2}$ was then used to estimate the LD decay (Breseghello and Sorrells 2006).

To identify candidate genes, we conducted a BLASTN search of the stable and pleiotropic MTAs that passed the FDR 0.05 threshold against the IWGSC RefSeq v. 1.0 (https://urgi.versailles.inra.fr/blast/). The genes within 1 Mbp of each SNP flanking region were screened based on the literature, and eight candidate genes were selected. Candidate gene annotations were obtained from Ensembl Plants release 103 (Howe et al. 2021). The expression patterns of two candidate genes, one controlling GY, GY stability, and NDVI, and another controlling CT3, were investigated in the Genevestigator software (www.genevestig ator.com, dataset: mRNA-Seq Gene Level Triticum aestivum, ref: IWGSCv1.1).

\section{Results}

\section{Field conditions in 2019 and 2020}

The average air temperature at the Gezira Research Farm ranged from 21.6 to $33.1{ }^{\circ} \mathrm{C}$ in 2019 and from 17.4 to $28.0^{\circ} \mathrm{C}$ in 2020 . The maximum temperature ranged from 30.8 to $43.0^{\circ} \mathrm{C}$ in 2019 and from 27.0 to $43.5^{\circ} \mathrm{C}$ in 2020 . As expected, the highest air temperatures were recorded toward the end of the growing season which corresponds to the reproductive stages in both years (Fig. 1a, b). Soil water potential decreased from near 0 before drought stress to near $-900 \mathrm{kPa}$ during severe HD stress in both seasons (Fig. 1c and d). 


\section{Effect of heat and combined heat-drought on trait variability under field conditions}

The genotype-by-environment $(\mathrm{G} \times \mathrm{E})$ interaction effects were significant for DH, GFD, GY, KPS, SPAD, and TKW in 2019, and for DM, GY, HI, and KPS in 2020 (Table S2). $\mathrm{DH}, \mathrm{HI}$, and $\mathrm{PH}$ had consistently higher heritability values (ranging from 0.70 to 0.89 ) than other traits, whereas BIO, CT1, CT2, CT3, SN, and SPAD had relatively low heritability (Table 1). Under HD condition, CT2 had moderate heritability, indicating a significant genetic control, whereas under $\mathrm{H}$ condition heritability was low, indicating low genetic control (Table 1). Except for CT2 in 2019, mean CT values tended to be lower under $\mathrm{HD}$ than under $\mathrm{H}$ condition. The DM, GFD, HI, and TKW values were also lower under $\mathrm{HD}$ than under $\mathrm{H}$ condition in both years. Consequently, GY was lower under $\mathrm{HD}$ than under $\mathrm{H}$, indicating a more severe effect of the HD condition (Table 1). The mean GY was $2735 \mathrm{~kg} \mathrm{ha}^{-1}$ under $\mathrm{H}$ and $1588 \mathrm{~kg} \mathrm{ha}^{-1}$ under HD in 2019 , and 3116 and $2297 \mathrm{~kg} \mathrm{ha}^{-1}$, respectively, in 2020 , indicating higher performance $(p<0.05)$ in 2020.

GY correlated significantly $(p<0.05)$ with most of the evaluated traits in both conditions in both years (Table S3). The GY-BIO and GY-HI correlations were consistently high, with correlation coefficients $(r)$ ranging from 0.564 to $0.742(p<0.01)$ in both conditions in both years. In contrast, all CT values tended to correlate negatively with most traits, including GY and BIO, under $\mathrm{H}$ in 2019 and under both conditions in 2020 (Table S3). Similarly, $\delta^{13} \mathrm{C}$ was negatively correlated with GY in both conditions, and with BIO, HI, and SPAD under HD in 2019. DH and GFD were negatively correlated in both conditions in both years (Table S3). We found low positive correlations between the two conditions in most traits except $\mathrm{DH}$ and $\mathrm{PH}$, which had high correlations ( $r=0.619-0.806$, Table S3), likely because the combined stress was imposed after heading.

Some MSD lines had higher average yield performance under $\mathrm{H}$ and $\mathrm{HD}$ conditions than the check cultivars, indicating considerable genetic gains (Fig. 2a). Some MSD lines had higher DR values than the check cultivars in both years (Fig. 2b). The decreasing yield trend under HD conditions is shown in Fig. 2c. Yield stability index was higher in some MSD lines than in the check cultivars, including N61 and 'Imam' (Fig. 2d). Lines with high GY and considerable GY stability are listed in Table S4.

\section{MTAs}

Since the same MTAs were obtained from both adjusted and unadjusted BLUEs, only the MTAs from the adjusted BLUEs are presented. Also, since all the MTAs found in the whole-genome GWAS were again found in the D genome-only GWAS, the MTAs with lowest FDR from either GWAS were selected (Table S5). A sample of results of the GLM and MLM models for both GWAS under HD in 2020 are shown in Table S6. Many significant MTAs were identified for various traits, with $12 \%$ and $27 \%$ of the MTAs passing the FDR 0.05 and 0.2 thresholds, respectively. In 2019, 75 MTAs for $\mathrm{H}, 4$ for HD, and 25 for DR passed the FDR tests; in 2020, 23 MTAs for H, 62 for HD, and 123 for DR passed (Fig. S1a). In total, 100 highly significant MTAs (FDR $<0.2)$ were associated with $\mathrm{H}, 68$ with HD, and 150 with DR in both years (including MTAs for GY stability index, Table S5). A summary of the MTAs (except those for GC, SPAD, and $\delta^{13} \mathrm{C}$ ) and chromosomal positions is shown in Fig. 3. The MTAs were found on 19 chromosomes, and $56.6 \%$ of all MTAs were found on chromosomes (Chrs.) 2D, 3D, 5D, and 7D (Fig. S1b). About $70.0 \%$ of all MTAs were for GY, KPS, NDVI, and CT (Fig. S1c). The MTAs identified for CT1, CT3, GY, KPS, and PH had the highest variation in allelic effect, which ranged from $6.7 \%$ to $52.1 \%$ (Fig. S1d). All identified MTAs are listed in Table S5. Representative Manhattan plots are shown in Fig. S2, and those for GY in the D genome alone are shown in Fig. 4. We identified 41 stable or pleiotropic MTAs (Table 2). Further analysis of some of the stable MTAs revealed the source of the SNP alleles (Ae. tauschii, 'Langdon', or N61) and the possible effect of the alleles on individual traits (Fig. 5). The positive alleles for PH, GY stability, and GY on the D genome originated from Ae. tauschii (Fig. 5).

\section{MTAs under $\mathrm{H}$ and HD}

Under $\mathrm{H}, 88.5 \%$ of the MTAs identified were for CT1, CT3, PH, NDVI, or GFD. Ten MTAs for CT3 explained between $19.8 \%$ and $35.1 \%$ of the variation, and six of them were collocated between 710 and $718 \mathrm{Mbp}$ on $\mathrm{Chr}$. 3A (Table S5). Two MTAs for GY $(7,940,688|\mathrm{~F}| 0-16$ and 998,513|F|0-66), located between 508 and $522 \mathrm{Mbp}$ on Chr. 3D, explained $10.6 \%$ and $11.8 \%$, respectively, of the phenotypic variation (Fig. 3, Table S5).

Under HD, 55\% of the MTAs identified were for CT1, NDVI, PH, and KPS. Nine MTAs on Chrs. 1D, 3D, 5D, and 7D were identified for CT1, seven of which were on $3 \mathrm{D}$ and $7 \mathrm{D}$ and explained $7.4 \%-11.4 \%$ of the variation (Fig. 3, Table S5). Among nine MTAs for NDVI, six were collocated on Chr. 2D (606-618 Mbp) and explained $9.2 \%-15.4 \%$ of the variation. Twelve MTAs were identified for KPS, three of which were collocated on Chr. 7D (345-384 Mbp) and explained on average 9.9\% of the variation. Six MTAs for GY explained $7.8 \%-14.5 \%$ of the variation (Fig. 3, Table S5). 


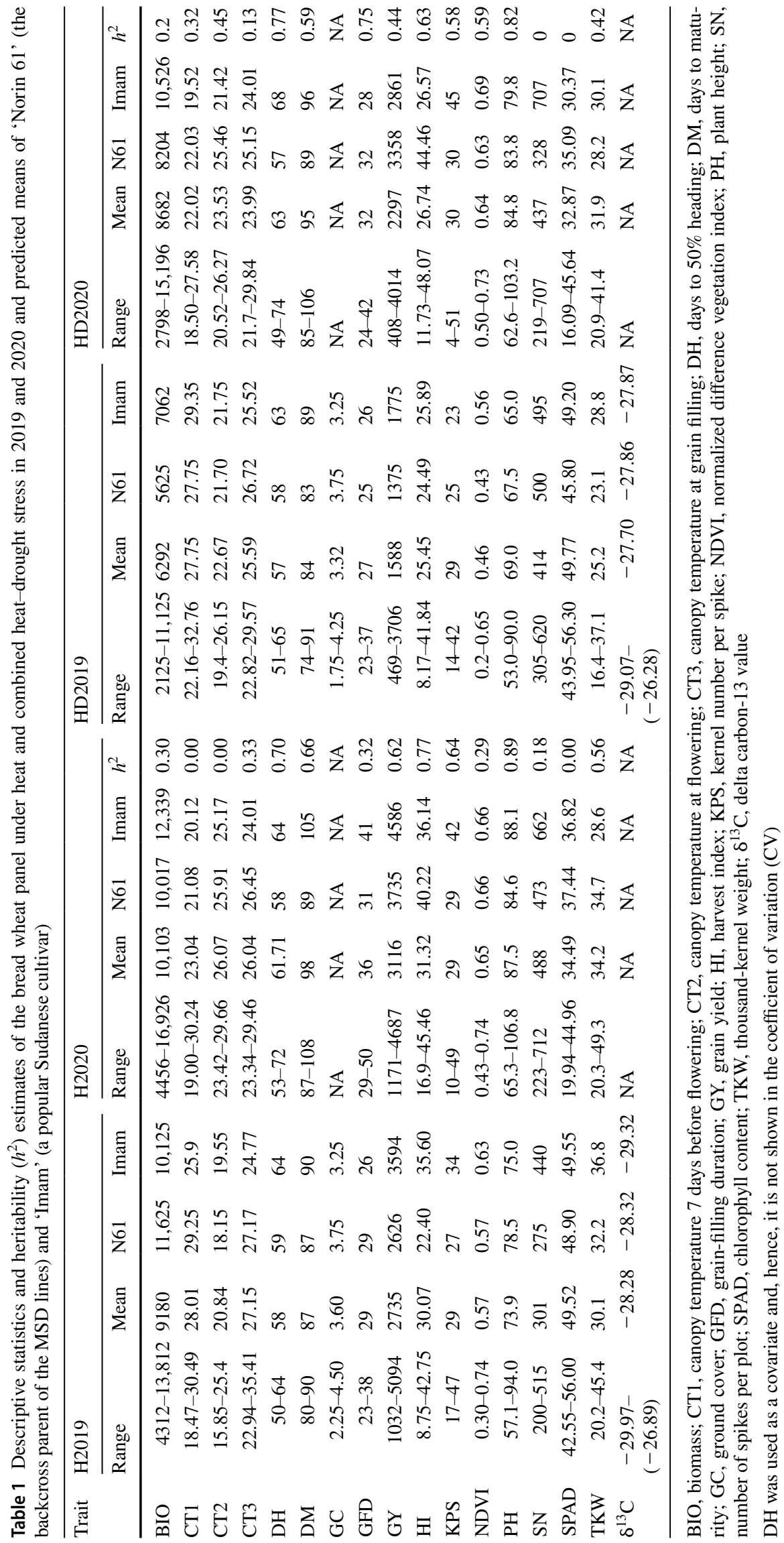


Fig. 2 Grain yield parameters of the investigated genotypes. a Average grain yield under heat (H) and heat-drought (HD) conditions, (b) drought response under heat stress (DR) in 2019 and 2020. Dashed gray lines intersect on 'Norin 61' (red circle), the backcross parent. Check cultivars: green circles, 'Imam'; blue circles, 'Fielder'; violet circles, 'Roelf'; and yellow circles, 'Gomria' (c, d) yield stability index across the four environments. $\mathbf{c}$ Each line represents mean grain yield for each genotype. The dashed line represents the population mean. Most of the genotypes showed a decreasing trend in grain yield under HD. d The most stable lines have a lower stability index $(<1.0)$ compared with the less stable lines. Some genotypes are more stable than 'Norin 61' and 'Imam'

Fig. 3 Physical positions of markers associated with evaluated traits under heat $(\mathrm{H})$ and combined heat-drought (HD) conditions, and in the drought response under heat stress (DR). Symbol size corresponds to the allelic effect of each MTA. BIO, biomass; CT3, canopy temperature at grain filling; $\mathrm{DM}$, days to maturity; GFD, grain-filling duration; GY, grain yield; HI, harvest index; KPS, kernel number per spike; NDVI, normalized difference vegetation index; $\mathrm{PH}$, plant height; SI, grain yield stability index; TKW, thousand-kernel weight a

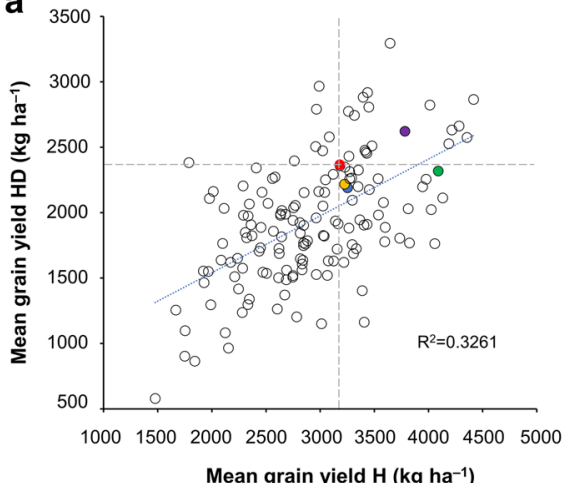

c

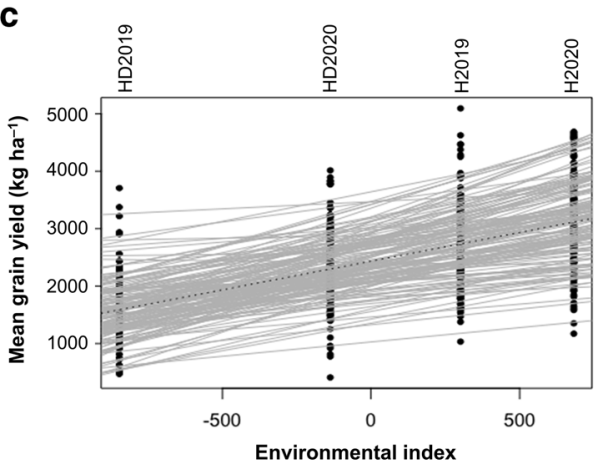

b

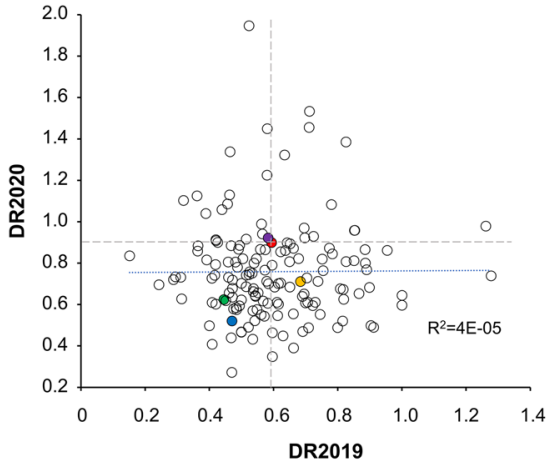

d

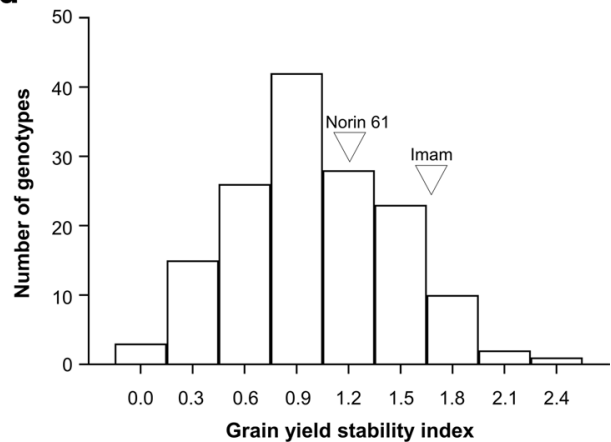

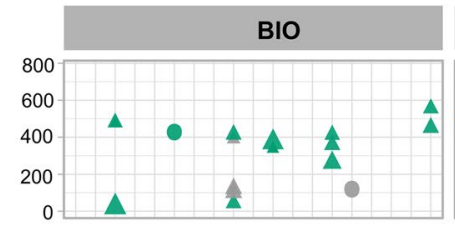
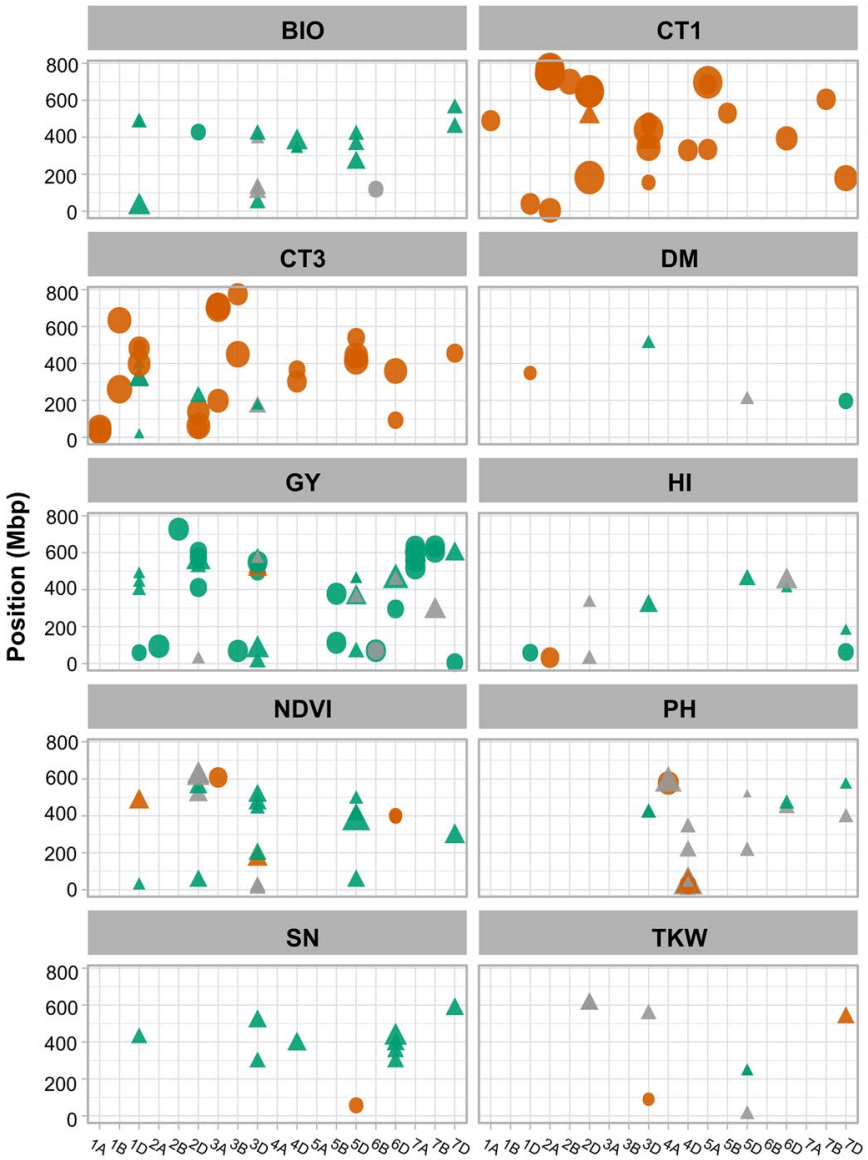

Chromosome
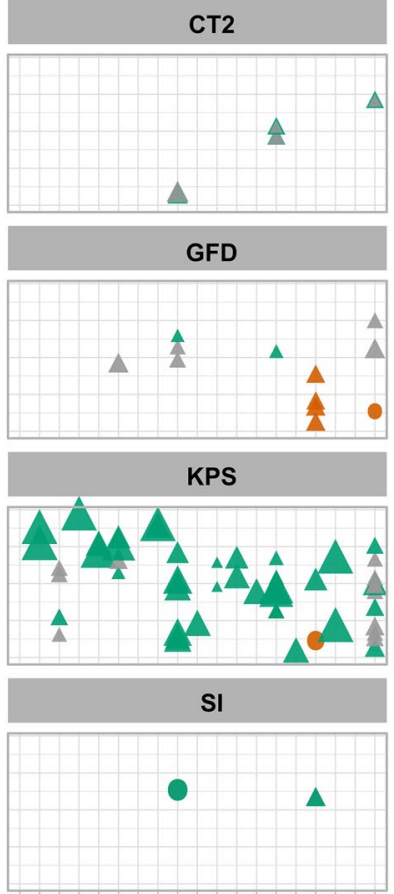

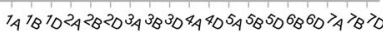

Year

- 2019

- 2020

DR

- $\mathrm{H}$ 

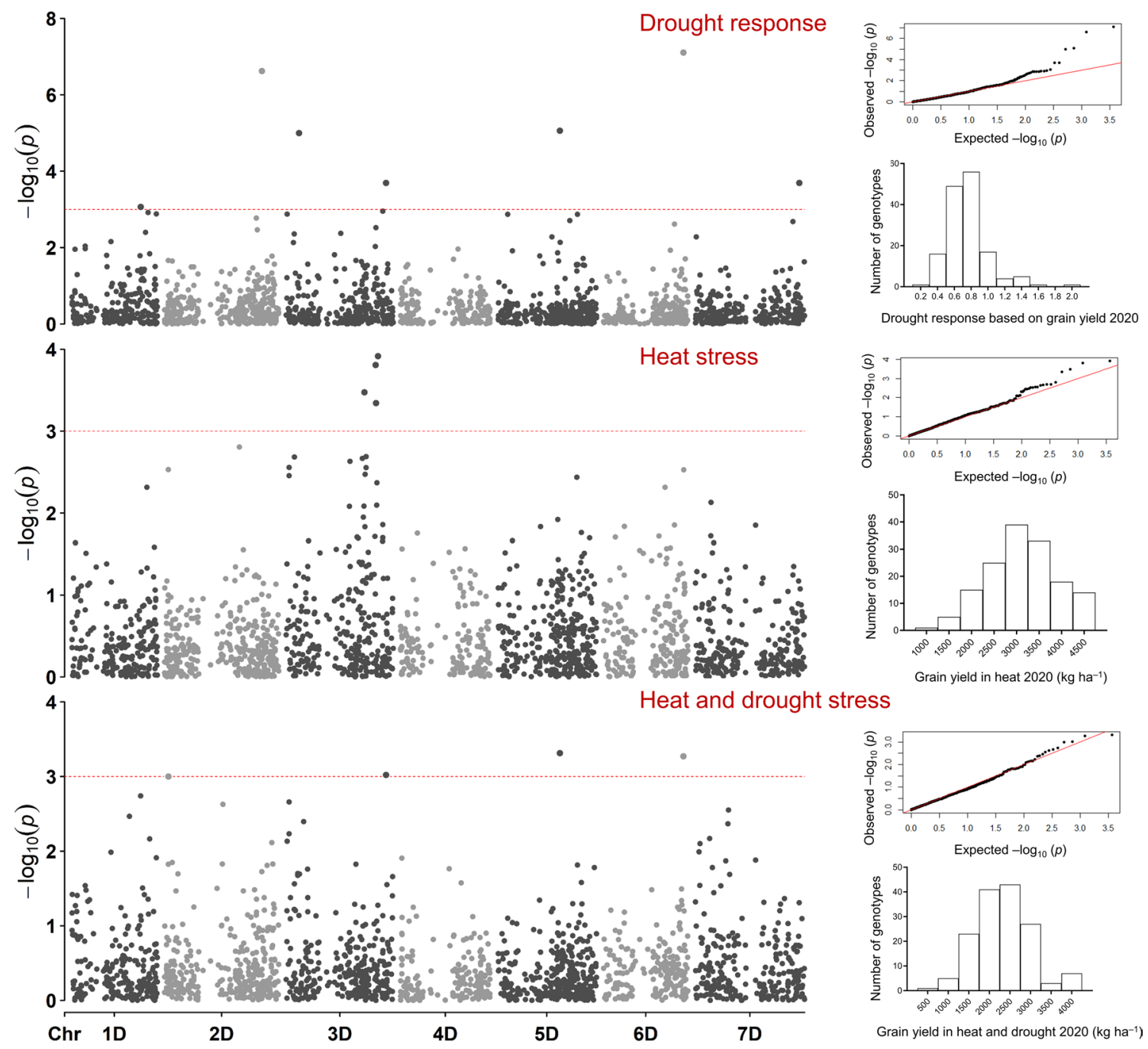

Fig. 4 Representative Manhattan plots for grain yield showing marker-trait associations in the D genome of bread wheat lines under heat or combined heat-drought stress, and in the drought response.

\section{MTAs for DR}

To estimate DR, the ratio of BLUEs obtained under HD to those obtained under $\mathrm{H}$ was used for GWAS. Although this ratio tends to oversimplify the complex relationship between heat and drought stress, it increased the statistical power of the analysis enabling the detection of many potentially important MTAs. These MTAs explained, on average, $14.7 \%$ of the phenotypic variation and $51.8 \%$ of the MTAs controlled GY and KPS. The MTAs for GY explained $7.2 \%-24.1 \%$ of the variation, whereas MTAs for KPS explained $7.10 \%-40.4 \%$. Six MTAs for KPS were collocated: $7,351,923|\mathrm{~F}| 0-56$ and $1,230,357|\mathrm{~F}| 0-39$ were located at $240.6 \mathrm{Mbp}$ on $\mathrm{Chr}$. 3B, 1,056,569|F|0-52 and $981,730|\mathrm{~F}| 0-67$ at $333.1 \mathrm{Mbp}$ on $\mathrm{Chr}$. 5D, and $2,252,899|\mathrm{~F}| 0-22$ and $3,024,415|\mathrm{~F}| 0-22$ at $408.0-408.6$
The distribution of grain yield and quantile-quantile plots of the genome-wide analysis are shown for each condition

Mbp on Chr. 5D (Fig. 3, Table S5). Two MTAs for GY $(1,125,420|\mathrm{~F}| 0-29$ and $1,072,095|\mathrm{~F}| 0-54)$ were collocated on Chr. 3D and explained $21.5 \%$ and $9.6 \%$, respectively, of the variation.

\section{Loci controlling plant phenology}

MTAs for PH were identified on Chrs. 4A and 3D-7D. Two MTAs (1,001,495|F|0-20 and 1,042,486|F|0-52) were collocated between 577.5 and $577.7 \mathrm{Mbp}$ on $\mathrm{Chr}$. 4A and explained $7.2 \%-9.7 \%$ of the variation under $\mathrm{H}$ and HD conditions. Four MTAs controlling PH were found between 25 and $37 \mathrm{Mbp}$ on Chr. 4D. Two of them were stable across H and HD: 1,079,306|F|0-62 was stable in both years and explained $9.5-25.7 \%$ of the variation, whereas $4,005,784|\mathrm{~F}| 0-33$ was stable in 2020 and explained 
Table 2 Stable and pleiotropic MTAs under heat $(\mathrm{H})$ and combined heat-drought (HD) conditions, and in the drought response (DR) in 2019 and 2020

\begin{tabular}{|c|c|c|c|c|c|c|c|}
\hline Environment & Year & FDR threshold & $\begin{array}{l}\text { Trait } \\
\text { (specific environment) }\end{array}$ & Marker & $\mathrm{Chr}$ & Position (Mbp) & Allelic effect (\%) \\
\hline DR & 2019 & 0.2 & GY, HI & $3,937,862|\mathrm{~F}| 0-24$ & $1 \mathrm{D}$ & 58.724191 & $12.8-13.7$ \\
\hline HD & 2020 & 0.2 & GY, HI & $3,020,847|\mathrm{~F}| 0-49$ & $2 \mathrm{D}$ & 23.110173 & $7.6-8.5$ \\
\hline $\mathrm{H}, \mathrm{HD}, \mathrm{DR}$ & 2020 & 0.05 & GY, SI, NDVI & $998,513|\mathrm{~F}| 0-66$ & $3 \mathrm{D}$ & 508.32788 & $11.2-20.3$ \\
\hline $\mathrm{HD}, \mathrm{DR}$ & 2020 & 0.05 & GY & $1,076,657|\mathrm{~F}| 0-26$ & $3 \mathrm{D}$ & 567.58126 & $7.7-9.7$ \\
\hline $\mathrm{HD}, \mathrm{DR}$ & 2020 & 0.05 & GY & $2,256,906|\mathrm{~F}| 0-13$ & $5 \mathrm{D}$ & 356.61467 & $8.5-13.5$ \\
\hline $\mathrm{H}, \mathrm{DR}$ & 2019,2020 & 0.2 & GY (DR2019), GFD(H2020) & $1,120,327|\mathrm{~F}| 0-5$ & $6 \mathrm{D}$ & 295.33974 & $11.4-15.5$ \\
\hline $\mathrm{HD}, \mathrm{DR}$ & 2020 & 0.05 & GY & $988,652|\mathrm{~F}| 0-39$ & $6 \mathrm{D}$ & 452.87905 & $8.5-19.3$ \\
\hline $\mathrm{H}, \mathrm{HD}$ & 2019 & 0.2 & GY & $1,218,720|\mathrm{~F}| 0-55$ & $7 \mathrm{~A}$ & 557.24618 & $14.6-22.1$ \\
\hline $\mathrm{HD}, \mathrm{DR}$ & 2019 & 0.2 & GY, BIO (HD2019) & $18,732,940|\mathrm{~F}| 0-36$ & $6 \mathrm{~B}$ & 69.312667 & $12.9-22.1$ \\
\hline HD & 2020 & 0.05 & TKW, NDVI & $1,161,247|\mathrm{~F}| 0-23$ & $2 \mathrm{D}$ & 614.01796 & $7.7-12.3$ \\
\hline HD & 2020 & 0.2 & TKW, NDVI & $4,734,029|\mathrm{~F}| 0-28$ & $2 \mathrm{D}$ & 614.17744 & $7.1-9.2$ \\
\hline $\mathrm{H}, \mathrm{DR}$ & 2019,2020 & 0.05 & TKW (H2019), KPS (DR2020) & $1,057,222|\mathrm{~F}| 0-51$ & $3 \mathrm{D}$ & 90.289806 & $9.3-18.9$ \\
\hline HD, DR & 2019,2020 & 0.2 & $\begin{array}{l}\text { TKW (HD2020), KPS } \\
\text { (DR2020), CT1(HD2019) }\end{array}$ & $985,748|\mathrm{~F}| 0-43$ & $3 \mathrm{D}$ & 550.71378 & $9.1-15.3$ \\
\hline DR & 2020 & 0.05 & TKW, KPS & $7,351,923|\mathrm{~F}| 0-56$ & $5 \mathrm{D}$ & 240.6867 & 7.4-9.6 \\
\hline $\mathrm{DR}$ & 2020 & 0.05 & TKW, KPS & $1,230,357|F| 0-39$ & $5 \mathrm{D}$ & 240.6867 & $7.3-9.6$ \\
\hline HD & 2020 & 0.05 & TKW, NDVI & $1,385,391|\mathrm{~F}| 0-63$ & $2 \mathrm{D}$ & 606.42916 & $10.9-15.5$ \\
\hline HD & 2020 & 0.2 & TKW, NDVI & $1,228,058|\mathrm{~F}| 0-36$ & $2 \mathrm{D}$ & 607.16567 & $9.7-10.5$ \\
\hline $\mathrm{HD}$ & 2020 & 0.05 & TKW, NDVI & $1,161,247|\mathrm{~F}| 0-23$ & $2 \mathrm{D}$ & 614.01796 & $7.7-12.3$ \\
\hline HD & 2020 & 0.2 & TKW, NDVI & $4,734,029|\mathrm{~F}| 0-28$ & $2 \mathrm{D}$ & 614.17744 & $7.1-9.2$ \\
\hline HD & 2020 & 0.05 & TKW, NDVI & $1,385,391|\mathrm{~F}| 0-63$ & $2 \mathrm{D}$ & 606.42916 & $10.8-15.521$ \\
\hline $\mathrm{H}, \mathrm{HD}$ & 2020 & 0.2 & KPS, CT1, NDVI & $994,213|\mathrm{~F}| 0-21$ & $2 \mathrm{D}$ & 511.70796 & $11.2-13.3$ \\
\hline DR & 2020 & 0.2 & $\mathrm{BIO}, \mathrm{CT} 2$ & $991,074|\mathrm{~F}| 0-56$ & $3 \mathrm{D}$ & 43.382158 & $8.9-12.6$ \\
\hline $\mathrm{HD}, \mathrm{DR}$ & 2020 & 0.2 & $\mathrm{BIO}$ (DR), CT2 & $986,326|\mathrm{~F}| 0-60$ & $5 \mathrm{D}$ & 359.1114 & $9.3-10.8$ \\
\hline $\mathrm{HD}, \mathrm{DR}$ & 2020 & 0.05 & $\mathrm{BIO}$ (DR), CT2 & $3,028,230|\mathrm{~F}| 0-33$ & $5 \mathrm{D}$ & 413.71439 & $7.7-10.7$ \\
\hline $\mathrm{HD}, \mathrm{DR}$ & 2020 & 0.2 & $\mathrm{BIO}$ (DR), CT2 & $1,012,073|\mathrm{~F}| 0-63$ & $7 \mathrm{D}$ & 556.34431 & $8.9-10.7$ \\
\hline $\mathrm{H}, \mathrm{HD}, \mathrm{DR}$ & 2019,2020 & 0.05 & $\mathrm{PH}$ & $1,079,306|\mathrm{~F}| 0-62$ & $4 \mathrm{D}$ & 25.701834 & $15.2-27.3$ \\
\hline $\mathrm{H}, \mathrm{HD}$ & 2020 & 0.2 & $\mathrm{PH}$ & $4,005,784|\mathrm{~F}| 0-33$ & $4 \mathrm{D}$ & 36.86672 & $7.2-9.7$ \\
\hline DR & 2020 & 0.2 & DM, GFD & $991,772|\mathrm{~F}| 0-64$ & $3 \mathrm{D}$ & 507.14502 & $7.9-8.0$ \\
\hline HD, DR & 2020 & 0.05 & $\mathrm{CT} 2$ & $2,251,455|\mathrm{~F}| 0-29$ & $3 \mathrm{D}$ & 55.135592 & $12.6-14.7$ \\
\hline HD, DR & 2020 & 0.05 & CT3 & $12,002,285|\mathrm{~F}| 0-11$ & $1 \mathrm{D}$ & 315.11177 & $10.6-12.3$ \\
\hline $\mathrm{H}, \mathrm{HD}$ & 2020 & 0.2 & CT3, NDVI & $1,015,501|\mathrm{~F}| 0-10$ & $3 \mathrm{D}$ & 164.82545 & $10.2-12.6$ \\
\hline $\mathrm{H}, \mathrm{DR}$ & 2019,2020 & 0.2 & CT3, NDVI & $2,250,763|\mathrm{~F}| 0-61$ & $5 \mathrm{D}$ & 410.7371 & $9.0-11.8$ \\
\hline $\mathrm{HD}, \mathrm{DR}$ & 2020 & 0.05 & SPAD & $1,236,663|\mathrm{~F}| 0-12$ & $5 \mathrm{D}$ & 344.28537 & $16.8-17.3$ \\
\hline HD & 2020 & 0.2 & NDVI & $1,228,058|\mathrm{~F}| 0-36$ & $2 \mathrm{D}$ & 607.16567 & $9.7-10.5$ \\
\hline
\end{tabular}

Traits without an environment in parenthesis were identified in the environment(s) and year(s) listed in the first and second columns, respectively. BIO, biomass; CT1, canopy temperature 7 days before flowering; CT2, canopy temperature at flowering; CT3, canopy temperature at grain filling; DM, days to maturity; GFD, grain-filling duration; GY, grain yield; HI, harvest index; KPS, kernel number per spike; NDVI, normalized difference vegetation index; PH, plant height; SI, GY stability index; SPAD, chlorophyll content; TKW, thousand-kernel weight

7.2-9.7\% of the variation in PH (Table S5). Eleven MTAs were identified for GFD and explained, on average, $10.3 \%$ of the variation. An MTA on Chr. 3D (991,772|F|0-64) was pleiotropic for DM in the DR in 2020, and an MTA on Chr. 6D $(1,120,327|\mathrm{~F}| 0-5)$ was pleiotropic for GY under $\mathrm{H}$ in 2020 (Table 2).

\section{Loci controlling leaf traits associated with GY traits}

Because leaf traits were correlated with GY and related traits (Table S3), we investigated the loci controlling CT, NDVI, and $\delta^{13} \mathrm{C}$. The heritability estimates for CT measurements were low, even zero in some cases, while those for $\delta^{13} \mathrm{C}$ 

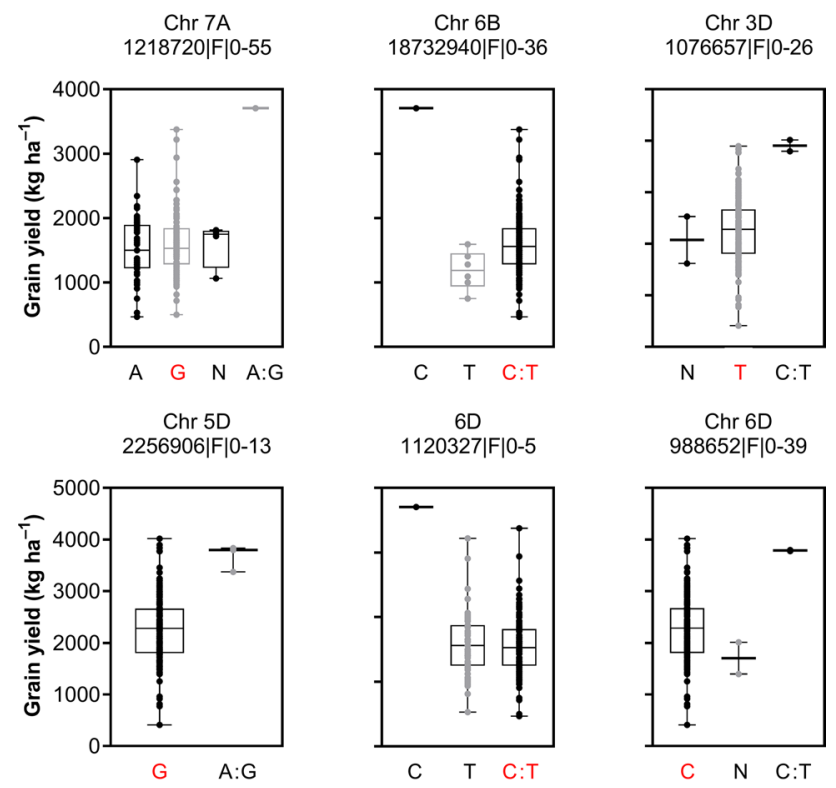

Chr 6D 988652|F|0-39
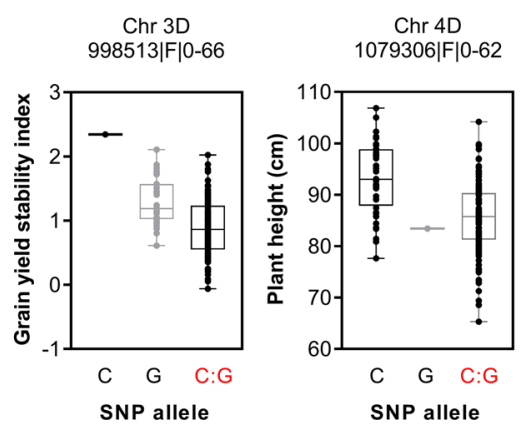

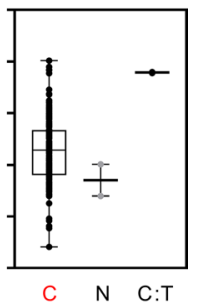

Chr 4D $3222279|\mathrm{~F}| 0-26$

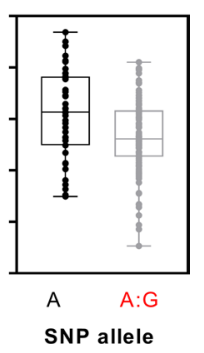

Fig. 5 Effect of selected stable marker-trait associations on grain yield, grain yield stability index, and plant height in a bread wheat population grown under heat or combined heat-drought stress. A, adenine; C, cytosine; $\mathrm{T}$, thymine; $\mathrm{G}$, guanine; N, unknown. Red alleles are those of the backcross parent of the population, 'Norin 61 '

could not be determined since $\delta^{13} \mathrm{C}$ was measured in only one season (Table 1). However, due to the importance of these traits for wheat breeding in hot, dry areas, we conducted GWAS analysis and found potentially useful MTAs. Most of the MTAs for leaf traits were found on Chrs. 2D, 3D, and 5D. Three loci were identified on Chr. 2D: the first locus (23-96 Mbp) harbored MTAs for $\delta^{13} \mathrm{C}, \mathrm{CT} 3$, NDVI, and HI, which explained $7.6 \%-30.6 \%$ of the variation; the second locus (511-554 Mbp) harbored MTAs for CT1, NDVI, KPS, and GY, which explained 7.6-17.7\%; and the third locus (606-614 Mbp) harbored MTAs for NDVI, TKW, and GY, which explained 7.1\%-16.2\%. The locus on Chr. 3D (155-171 Mbp) harbored MTAs for CT1, CT3, and NDVI, which explained on average $9.9 \%$ of the variation. The locus on Chr. 5D (407-413 Mbp) contained MTAs for CT1, CT2, CT3, NDVI, and BIO, which explained $7.7 \%-32.8 \%$ of the variation. As all these loci on Chrs. 2D, 3D, and 5D also harbored MTAs for GY and related traits under $\mathrm{H}, \mathrm{HD}$, and DR

(Fig. 3, Table S5), they may be important for yield improvement for $\mathrm{H}$ and drought stress resilience.

\section{Loci controlling GY, KPS, and TKW}

We identified a locus on Chr. 3D (521-549 Mbp) controlling GY and explaining 9.6\%-21.5\% of the variation under $\mathrm{H}$ and DR, and another locus on Chr. 3D (79-90 Mbp) common to KPS and TKW explaining 9.3-22.4\% of the variation under $\mathrm{H}$ and DR (Table S5). We identified another locus common to KPS and TKW on Chr. 5D (240.6 Mbp) explaining on average $8.5 \%$ of the variation in DR, and a locus controlling GY and KPS on Chr. 7A (517-556 Mbp) explaining a relatively high $(21.0 \%-40.3 \%)$ proportion of the variation under DR.

\section{Candidate genes}

The markers in the $\mathrm{AB}$ genome are in high $\mathrm{LD}$ with $\mathrm{LD}$ decay extending up to $131 \mathrm{Mbp}$, whereas those in the $\mathrm{D}$ genome have an LD decay at $1.1 \mathrm{Mbp}$. A candidate gene for GY, GY stability, and NDVI was identified as a gibberellin-regulating gene (GA20ox TraesCS3D02G393900) on Chr. 3D (998,513|F|0-66, 508.3 Mbp). A candidate gene for CT3 was identified as a gene involved in CaaX prenylation (CaaX prenyl protease 2, TraesCS1D02G228400) on Chr. 1D $(12,002,285|\mathrm{~F}| 0-11,315.1 \mathrm{Mbp})$. Their expression patterns show highest expression in the endosperm (GA20ox, Fig. S3) and in the roots, shoots and inflorescences ( $\mathrm{CaaX}$ prenyl protease 2, Fig. S4). These relative expressions were sourced from many independent studies involving different genotypes, growth stages, and conditions implemented in Genevestigator. A list of the candidate genes is shown in Table S7.

\section{Discussion}

The strong $\mathrm{G} \times \mathrm{E}$ interaction effect $(p<0.001$, Table S2) on most traits confirmed the high genetic diversity of the panel. Under HD, GY was drastically reduced (up to 58\% of that under $\mathrm{H}$ ), highlighting the detrimental effect of HD under natural field conditions. Similar observations have been reported under field (Pradhan et al. 2012; Liu et al. 2019) and controlled conditions (Prasad et al. 2011; Schmidt et al. 2020). The moderate to high heritability estimates for most of the traits were similar to those in Sukumaran et al. (2018) under separate $\mathrm{H}$, drought stresses, and yield potential conditions in Mexico, reflecting the genetic control of these traits across environments. The correlations observed between most of the evaluated traits suggest an association among these traits at the genetic level, which improves selection efficiency (Shimelis and Shiringani 2010). The weak 
positive correlations of individual traits between $\mathrm{H}$ and $\mathrm{HD}$ indicate that genotypes that performed well under $\mathrm{H}$ were strongly affected by HD (Table S3). However, some genotypes performed relatively well under both conditions and are promising for further breeding (Fig. 2). Their good performance may be attributed to the effect of different SNP alleles. For example, genotypes with the $\mathrm{R}$ allele at 1,218,720|F|0-55 on Chr. 7A, C allele for 18,732,940|F|0-36 on Chr. 6B, and Y allele for 1,076,657|F|0-26 on Chr. 3D had higher GY across the environments than that of other genotypes, including N61 (Fig. 5).

Among the leaf traits, CT1-CT3 and $\delta^{13} \mathrm{C}$ showed negative correlation trends with GY and related traits, whereas NDVI showed positive correlation trends, especially with BIO (Table S3). Similar results have been reported under field conditions (Rutkoski et al. 2016; Sukumaran et al. 2018), indicating the effectiveness of these traits for improving selection efficiency for GY. Rutkoski et al. (2016) reported the use of CT and NDVI measurements to improve GY prediction accuracy by up to $70 \%$, whereas an earlier study in Spain (Royo et al. 2002) reported that carbon isotope discrimination was more effective than canopy temperature depression in assessing genotypic variation in GY. Itam et al. (2020b) reported an increasing trend of CT and $\delta^{13} \mathrm{C}$ under progressive drought stress due to stomatal regulation. Overall, a combination of CT, NDVI, and $\delta^{13} \mathrm{C}$ will further improve the accuracy of selection for GY in wheat.

The genetic basis of quantitative traits such as $\mathrm{H}$ and HD resilience is complex and requires detailed genomic analyses. In GWAS, we set DH as a covariate to minimize any possible confounding effect of plant phenology. Many MTAs are reportedly dependent on DH (Sukumaran et al. 2018; Schmidt et al. 2020), but $99 \%$ of the MTAs identified here were independent of $\mathrm{DH}$, mainly because the selection of our wheat panel was based on similar DH. No significant correlation was found between DH and GY (Table S3). Therefore, we consider this wheat panel to be suitable for mining novel QTLs for H and HD stress resilience without the confounding effect of plant phenology. We found stable MTAs across two or more conditions and pleiotropic MTAs controlling more than one trait, indicating the stability of the associated QTLs across environments and common regulation of these traits (Tables 2, S5). A plot of stable MTAs showed the effect of SNP alleles on the evaluated traits, indicating that positive alleles for $\mathrm{GY}$ on Chrs. $6 \mathrm{~B}$ and 7A were derived from 'Langdon', the durum wheat cultivar used as a bridge during the crosses (Fig. 5). Itam et al. (2021) reported that the introgressed segments from 'Langdon' (AABB) contribute to the A and $\mathrm{B}$ genome diversity of the panel. Conversely, the positive alleles in the $\mathrm{D}$ genome derived from Ae. tauschii were associated with high GY stability index and GY under H and HD (Fig. 5). Some MSD lines and N61 contained a negative allele for $\mathrm{PH}$, supporting the fact that
N61 harbors the dwarfing genes that were important for the Green Revolution (Tsujimoto 2021). Overall, genotypes carrying the positive alleles for GY and GY stability index and negative alleles for PH may be selected for future breeding.

\section{Genetic control of leaf traits}

QTLs on Chrs. 2D (23-47, 511-554, and 606-614 Mbp), 3D (155-171 Mbp), and 5D (407-413 Mbp) were identified for most leaf traits, including CT1-CT3 and NDVI. The Chr. 2D locus at 606-614 Mbp (130.8 cM) was previously reported for GY under HD in a synthetic-derived parent/ elite line RIL population (Liu et al. 2019) and is potentially novel for NDVI. The Chr. 2D locus at 23-47, (20.9 cM) was previously reported for CT depression in recombinant inbred lines under heat stress (Mondal et al. 2015), for GY in doubled haploids under heat stress (Bennett et al. 2012), and for carbon isotope discrimination in doubled haploids under rainfed and irrigated environments (Rebetzke et al. 2008). In this study, the Chr. 2D locus at $96 \mathrm{Mbp}$ controlled the $\delta^{13} \mathrm{C}$ value, an important physiological trait for evaluating stress response. However, owing to the limitations of $\delta^{13} \mathrm{C}$ or carbon isotope discrimination (Dixon et al. 2019), direct selection using carbon isotope traits alone may offer limited opportunities for wheat improvement. In this study, heritability estimates for $\mathrm{CT}$ were low, while those for $\delta^{13} \mathrm{C}$ could not be determined (Table 1). Therefore, the QTLs for CT and $\delta^{13} \mathrm{C}$ only show a potential trend and must be carefully validated before utilization. Taken together, a combination of $\delta^{13} \mathrm{C}$ and the easy-to-measure leaf traits such as $\mathrm{CT}$ and NDVI will likely improve selection efficiency.

One candidate gene regulating canopy temperature at grain filling (CT3) was CaaX prenyl protease 2 (TraesCS1D02G228400) (Fig. S4). CaaX prenyl proteases are involved in the prenylation of CaaX proteins, a step essential for protein-membrane interactions, plant development, and stress signaling, especially in abscisic acid signaling in Arabidopsis (Bracha-Drori et al. 2008) and wheat (Zhang et al. 2015). In the bread wheat lines, this gene may play a role in stress signaling and stomatal regulation under $\mathrm{H}$ and HD stresses, resulting in canopy temperature regulation. Further research is needed for the applicability of this gene to wheat breeding. QTLs for CT promote downward root growth $(30-90 \mathrm{~cm})$ under drought stress and root spread close to the soil surface under $\mathrm{H}$, a root distribution strategy for wheat adaptation to both stresses (Pinto and Reynolds 2015). However, HD would likely result in a tradeoff between root elongation and spread to optimize plant-water relations. In our study, the decreasing trend of CT2 and CT3 suggests that most of the wheat lines maintained lower canopy temperature under HD than in $\mathrm{H}$ stress. Low canopy temperature has been linked to high GY in wheat under separate $\mathrm{H}$ and drought stress conditions (Pinto and Reynolds 
2015). The QTLs on Chrs. 2D, 3D, and 5D may regulate resilience to $\mathrm{H}$ and $\mathrm{HD}$ and are potentially useful for wheat breeding.

\section{Genetic control of GY and related traits}

In wheat, GY is the most important trait. A locus on Chr. 3D (521-549 Mbp) controlled GY alone, a locus on Chr. 7A (517-556 Mbp) controlled GY and KPS, and two loci on Chrs. 3D (79-90 Mbp) and 5D (240.6 Mbp) each controlled KPS and TKW under $\mathrm{H}$ and HD stresses. The Chr. 7A loci (517-556 Mbp, 80.1-83.3 cM) was previously reported for GY in elite European varieties under moderate water deficit (Touzy et al. 2019). Information on other loci is not clear. Taken together, these loci explained up to $40.3 \%$ of the variation in GY and related traits under $\mathrm{H}$ and $\mathrm{HD}$ and thus they offer great potential for improvement of wheat climate resilience. This potential reflects the importance of harnessing Ae. tauschii diversity for climate resilience breeding using the synthetic derivative approach (Tsujimoto et al. 2015). Further analysis and validation of individual QTLs using a recombinant population would be needed to better understand the effects of the pleiotropic QTLs on individual traits. Also, the use of functional markers such as kompetitive allele-specific PCR (Fang et al. 2020; Rasheed et al. 2016) markers may facilitate selection and further breeding.

It is worthy of note that an MTA for GY stability index on Chr. 3D (998,513|F|0-66, 508.3 Mbp) was linked to the gene TraesCS3D02G393900, which is orthologous to gibberellin20-oxidase (GA20ox) in Zea mays L. (Zm00001d007894). GA20ox3 functions in gibberellin biosynthesis, and gibberellins play a central role in plant responses to abiotic stresses by integrating multiple hormone signaling pathways (Colebrook et al. 2014). Similarly, gibberellin-sensitive $R h t$ alleles (controlling plant height) have been reported to confer tolerance to heat and drought stress in wheat (Alghabari et al. 2016). We hypothesize that TraesCS3D02G393900 on Chr. 3D may favorably alter gibberellin content, ultimately resulting in higher GY stability under $\mathrm{H}$ and HD conditions. This offers a potential for developing climateresilient wheat cultivars by optimizing gibberellin homeostasis. However, further investigations are needed to test this hypothesis by exploiting the diversity in gibberellinregulating genes in wheat. Our database search revealed that TraesCS3D02G393900 is mainly expressed during the late vegetative and reproductive stages, with highest expression in the endosperm (Fig. S3) (Pearce et al. 2015). Similar expression patterns were reported in its orthologs in Z. mays (Zm00001d007894, Yousaf et al. 2019), Oryza sativa L. (LOC_Os07g07420, Qin et al. 2013), and Hordeum vulgare L. (HORVU3Hr1G089980, Betts et al. 2020) indicating a similar function of these genes among members of the grass family. Moreover, as the candidate genes were found at a distance less than the LD decay (LD decay for D genome $=1.1 \mathrm{Mbp}$, for $\mathrm{AB}$ genome $=131 \mathrm{Mbp}$ ), they may be useful for further breeding.

\section{Conclusion}

The wheat MSD panel used in this study represents the diversity of 37 Ae. tauschii accessions, and the study provides insights into the utilization of high-diversity breeding panels for wheat improvement. Since GWAS studies under HD in field conditions are scarce, the identified candidate genes, alleles, and QTLs will potentially serve as genomic landmarks for breeding to improve wheat adaptation to $\mathrm{H}$ and HD stresses under climate change.

Supplementary Information The online version contains supplementary material available at https://doi.org/10.1007/s00122-021-03969-x.

Acknowledgements The authors are thankful to the management and staff of the Gezira Research Farm, Wad Medani, Sudan, for field management and technical assistance and Dr. M. Tsubo (Arid Land Research Center, Tottori University) for kindly providing the relative humidity data.

Authors' Contribution Statement HT, YG, RM, and MI conceived the project; HT provided materials and acquired funding; MI, IT, RM, and YG designed the plot layout and planned the study; MI, IT, RM, $\mathrm{KA}$, and YG performed field activities; RM measured carbon isotope composition; MI analyzed the data, prepared figures with input from YY, and wrote a draft of the manuscript; HT and KA supervised the study. All authors reviewed, edited, and agreed to the published version of the manuscript.

Funding This study was jointly funded by Science and Technology Research Partnership for Sustainable Development (SATREPS, JPMJSA1805) by Japan Science and Technology Agency, Kakenhi (JP18H02179) by Japan Society for the Promotion of Science, and the Marginal Region Agriculture Project of Tottori University.

\section{Declarations}

Conflict of interest The authors declare that there is no conflict of interest.

Availability of data and material The genomic data are available at the Dryland Public Research Database of Tottori University (https:// docs.google.com/spreadsheets/d/1tmihGw-xZqKt7NUtCqca-_vzVIa vvJXm/edit?usp $=$ sharing\&ouid $=112779701721431756615 \&$ rtpof $=$ true $\&$ sd $=$ true)

Open Access This article is licensed under a Creative Commons Attribution 4.0 International License, which permits use, sharing, adaptation, distribution and reproduction in any medium or format, as long as you give appropriate credit to the original author(s) and the source, provide a link to the Creative Commons licence, and indicate if changes were made. The images or other third party material in this article are included in the article's Creative Commons licence, unless indicated otherwise in a credit line to the material. If material is not included in 
the article's Creative Commons licence and your intended use is not permitted by statutory regulation or exceeds the permitted use, you will need to obtain permission directly from the copyright holder. To view a copy of this licence, visit http://creativecommons.org/licenses/by/4.0/.

\section{References}

Alghabari F, Ihsan MZ, Khaliq A et al (2016) Gibberellin-sensitive $R h t$ alleles confer tolerance to heat and drought stresses in wheat at booting stage. J Cereal Sci 70:72-78. https://doi.org/10.1016/j. jcs.2016.05.016

Alvarado G, Rodríguez FM, Pacheco A et al (2020) META-R: a software to analyze data from multi-environment plant breeding trials. Crop J 8:745-756. https://doi.org/10.1016/j.cj.2020.03.010

Benjamini Y, Hochberg Y (1995) Controlling the false discovery rate: a practical and powerful approach to multiple testing. J R Stat Soc Ser B 57:289-300. https://doi.org/10.1111/j.25176161.1995.tb02031.x

Bennett D, Reynolds M, Mullan D et al (2012) Detection of two major grain yield QTL in bread wheat (Triticum aestivum L.) under heat, drought and high yield potential environments. Theor Appl Genet 125:1473-1485. https://doi.org/10.1007/ s00122-012-1927-2

Betts NS, Dockter C, Berkowitz O et al (2020) Transcriptional and biochemical analyses of gibberellin expression and content in germinated barley grain. J Exp Bot 71:1870-1884. https://doi. org/10.1093/jxb/erz546

Bracha-Drori K, Shichrur K, Lubetzky TC, Yalovsky S (2008) Functional analysis of Arabidopsis postprenylation CaaX processing enzymes and their function in subcellular protein targeting. Plant Physiol 148:119-131. https://doi.org/10.1104/pp.108.120477

Bradbury PJ, Zhang Z, Kroon DE et al (2007) TASSEL: Software for association mapping of complex traits in diverse samples. Bioinformatics 23:2633-2635. https://doi.org/10.1093/bioinforma tics/btm308

Breseghello F, Sorrells ME (2006) Association mapping of kernel size and milling quality in wheat (Triticum aestivum L.) cultivars. Genetics 172:1165-1177. https://doi.org/10.1534/genetics. 105.044586

Colebrook EH, Thomas SG, Phillips AL, Hedden P (2014) The role of gibberellin signalling in plant responses to abiotic stress. J Exp Biol 217:67-75

Dixon LS, Godoy JV, Carter AH (2019) Evaluating the utility of carbon isotope discrimination for wheat breeding in the Pacific Northwest. Plant Phenomics. https://doi.org/10.34133/2019/4528719

Elbashir AAE, Gorafi YSA, Tahir ISA et al (2017) Genetic variation in heat tolerance-related traits in a population of wheat multiple synthetic derivatives. Breed Sci 67:483-492. https://doi.org/10. 1270/jsbbs. 17048

Elhadi GMI, Kamal NM, Gorafi YSA et al (2021) Exploitation of tolerance of wheat kernel weight and shape-related traits from Aegilops tauschii under heat and combined heat-drought stresses. Int J Mol Sci 22:1830. https://doi.org/10.3390/ijms22041830

Elsheikh ERA, Schultz B, Adam HS, Haile AM (2015) Crop water productivity for sunflower under different irrigation regimes and plant spacing in Gezira Scheme, Sudan. J Agric Environ Int Dev 109:221-233. https://doi.org/10.12895/jaeid.20152.346

Fang T, Lei L, Li G et al (2020) Development and deployment of KASP markers for multiple alleles of Lr34 in wheat. Theor Appl Genet 133:2183-2195. https://doi.org/10.1007/s00122-020-03589-x

Finlay KW, Wilkinson GN (1963) The analysis of adaptation in a plantbreeding programme. Aust J Agric Res 14:742-754. https://doi. org/10.1071/AR9630742
Food and Agriculture Organization of the United Nations (2020) FAO cereal supply and demand brief I World Food Situation I Food and Agriculture Organization of the United Nations. In: 05/03/2020. http://www.fao.org/worldfoodsituation/csdb/en/. Accessed 18 Feb 2021

Gbegbelegbe S, Cammarano D, Asseng S et al (2017) Baseline simulation for global wheat production with CIMMYT mega-environment specific cultivars. Field Crops Res 202:122-135. https://doi. org/10.1016/j.fcr.2016.06.010

Gorafi YSA, Kim JS, Elbashir AAE, Tsujimoto H (2018) A population of wheat multiple synthetic derivatives: an effective platform to explore, harness and utilize genetic diversity of Aegilops tauschii for wheat improvement. Theor Appl Genet 131:1615-1626. https://doi.org/10.1007/s00122-018-3102-x

Howe KL, Achuthan P, Allen J et al (2021) Ensembl 2021. Nucleic Acids Res 49:D884-D891. https://doi.org/10.1093/nar/gkaa942

Iizumi T, Ali-Babiker I-EA, Tsubo M et al (2021) Rising temperatures and increasing demand challenge wheat supply in Sudan. Nat Food 2:19-27. https://doi.org/10.1038/s43016-020-00214-4

Itam M, Abdelrahman M, Yamasaki Y et al (2020a) Aegilops tauschii introgressions improve physio-biochemical traits and metabolite plasticity in bread wheat under drought stress. Agronomy 10:117. https://doi.org/10.3390/agronomy 10101588

Itam M, Mega R, Tadano S et al (2020b) (2020b) Metabolic and physiological responses to progressive drought stress in bread wheat. Sci Reports 101(10):1-14. https://doi.org/10.1038/ s41598-020-74303-6

Itam MO, Gorafi YSA, Tahir ISA, Tsujimoto H (2021) Genetic variation in drought resilience-related traits among wheat multiple synthetic derivative lines: insights for climate resilience breeding. Breed Sci 71:435-443. https://doi.org/10.1270/jsbbs.20162

Liu C, Sukumaran S, Claverie E et al (2019) Genetic dissection of heat and drought stress QTLs in phenology-controlled syntheticderived recombinant inbred lines in spring wheat. Mol Breed 39:1-18. https://doi.org/10.1007/s11032-019-0938-y

Matsuoka Y, Nasuda S (2004) Durum wheat as a candidate for the unknown female progenitor of bread wheat: An empirical study with a highly fertile $\mathrm{F}_{1}$ hybrid with Aegilops tauschii Coss. Theor Appl Genet 109:1710-1717. https://doi.org/10.1007/ s00122-004-1806-6

Mondal S, Mason RE, Huggins T, Hays DB (2015) QTL on wheat (Triticum aestivum $\mathrm{L}$.) chromosomes $1 \mathrm{~B}, 3 \mathrm{D}$ and $5 \mathrm{~A}$ are associated with constitutive production of leaf cuticular wax and may contribute to lower leaf temperatures under heat stress. Euphytica 201:123-130. https://doi.org/10.1007/s10681-014-1193-2

Ogbonnaya FC, Abdalla O, Mujeeb-Kazi A et al (2013) Synthetic hexaploids: harnessing species of the primary gene pool for wheat improvement. Plant Breed Rev 37:35-122. https://doi.org/10. 1002/9781118497869.ch2

Pask A, Pietragalla J, Mullan D (2012) Physiological breeding II: a field guide to wheat phenotyping. CIMMYT, Mexico City

Pearce S, Huttly AK, Prosser IM et al (2015) Heterologous expression and transcript analysis of gibberellin biosynthetic genes of grasses reveals novel functionality in the GA3ox family. BMC Plant Biol 15:130. https://doi.org/10.1186/s12870-015-0520-7

Pennisi E (2008) The blue revolution, drop by drop, gene by gene. Science 320:171-173. https://doi.org/10.1126/science.320.5873.171

Pinto RS, Reynolds MP (2015) Common genetic basis for canopy temperature depression under heat and drought stress associated with optimized root distribution in bread wheat. Theor Appl Genet 128:575-585. https://doi.org/10.1007/s00122-015-2453-9

Pradhan GP, Prasad PVV, Fritz AK et al (2012) Effects of drought and high temperature stress on synthetic hexaploid wheat. Funct Plant Biol 39:190-198. https://doi.org/10.1071/FP11245

Prasad PVV, Pisipati SR, Momčilović I, Ristic Z (2011) Independent and combined effects of high temperature and drought stress 
during grain filling on plant yield and chloroplast EF-Tu Expression in Spring Wheat. J Agron Crop Sci 197:430-441. https://doi. org/10.1111/j.1439-037X.2011.00477.x

Qaseem MF, Qureshi R, Shaheen H, Shafqat N (2019) Genome-wide association analyses for yield and yield-related traits in bread wheat (Triticum aestivum L.) under pre-anthesis combined heat and drought stress in field conditions. PLoS ONE 14:e0213407. https://doi.org/10.1371/journal.pone.0213407

Qin X, Liu JH, Zhao WS et al (2013) Gibberellin 20-oxidase gene OsGA20ox3 regulates plant stature and disease development in rice. Mol Plant-Microbe Interact 26:227-239. https://doi.org/10. 1094/MPMI-05-12-0138-R

Rasheed A, Wen W, Gao F et al (2016) Development and validation of KASP assays for genes underpinning key economic traits in bread wheat. Theor Appl Genet 129:1843-1860. https://doi.org/ 10.1007/s00122-016-2743-x

Rebetzke GJ, Condon AG, Farquhar GD et al (2008) Quantitative trait loci for carbon isotope discrimination are repeatable across environments and wheat mapping populations. Theor Appl Genet 118:123-137. https://doi.org/10.1007/s00122-008-0882-4

Reynolds M, Tattaris M, Cossani CM et al (2015) Exploring genetic resources to increase adaptation of wheat to climate change. In: Ogihara Y, Takumi S, Handa H (eds) Advances in wheat genetics: from genome to field. Springer Japan, Tokyo, pp 355-368. https:// doi.org/10.1007/978-4-431-55675-6_41

Royo C, Villegas D, García del Moral LF et al (2002) Comparative performance of carbon isotope discrimination and canopy temperature depression as predictors of genotype differences in durum wheat yield in Spain. Aust J Agric Res 53:561-569. https://doi. org/10.1071/AR01016

Rutkoski J, Poland J, Mondal S et al (2016) Canopy temperature and vegetation indices from high-throughput phenotyping improve accuracy of pedigree and genomic selection for grain yield in wheat. G3 Genes. Genomes Genet 6:2799-2808. https://doi.org/ $10.1534 / \mathrm{g} 3.116 .032888$

Saghai-Maroof MA, Soliman KM, Jorgensen RA, Allard RW (1984) Ribosomal DNA spacer-length polymorphisms in barley: mendelian inheritance, chromosomal location, and population dynamics. Proc Natl Acad Sci USA 81:8014-8018. https://doi.org/10.1073/ pnas.81.24.8014

Sansaloni C, Petroli C, Jaccoud D et al (2011) Diversity arrays technology (DArT) and next-generation sequencing combined: genomewide, high throughput, highly informative genotyping for molecular breeding of Eucalyptus. BMC Proc 5(Suppl 7):P54. https://doi. org/10.1186/1753-6561-5-s7-p54

Schmidt J, Tricker PJ, Eckermann P et al (2020) Novel alleles for combined drought and heat stress tolerance in wheat. Front Plant Sci 10:1-14. https://doi.org/10.3389/fpls.2019.01800

Shimelis H, Shiringani R (2010) Variance components and heritabilities of yield and agronomic traits among cowpea genotypes. Euphytica 176:383-389. https://doi.org/10.1007/s10681-010-0222-z
Sukumaran S, Reynolds MP, Sansaloni C (2018) Genome-wide association analyses identify QTL hotspots for yield and component traits in durum wheat grown under yield potential, drought, and heat stress environments. Front Plant Sci 9:81. https://doi.org/10. 3389/fpls.2018.00081

Touzy G, Rincent R, Bogard M et al (2019) Using environmental clustering to identify specific drought tolerance QTLs in bread wheat (T. aestivum L.). Theor Appl Genet 132:2859-2880. https://doi. org/10.1007/s00122-019-03393-2

Tricker PJ, Elhabti A, Schmidt J, Fleury D (2018) The physiological and genetic basis of combined drought and heat tolerance in wheat. J Exp Bot 69:3195-3210. https://doi.org/10.1093/jxb/ ery081

Tsujimoto H (2021) Gene-mining asian wheat to feed the population in the 21st century. Plant Cell Physiol 62:1-2. https://doi.org/10. 1093/pcp/pcaa158

Tsujimoto H, Sohail Q, Matsuoka Y (2015) Broadening the genetic diversity of common and durum wheat for abiotic stress tolerance breeding. In: Ogihara Y, Takumi S, Handa H (eds) Advances in wheat genetics: from genome to field. Springer Japan, Tokyo, pp 233-238. https://doi.org/10.1007/978-4-431-55675-6_25

Turner S (2018) qqman: an R package for visualizing GWAS results using Q-Q and manhattan plots. J Open Source Softw 3:731. https://doi.org/10.1101/005165

Yousaf MJ, Hussain A, Hamayun M, et al (2019) Phytohormonal crosstalk modulate Bipolaris sorokiniana (Scc.)interaction with Zea mays. bioRxiv 847061. https://doi.org/10.1101/847061

Yu J, Pressoir G, Briggs WH et al (2006) A unified mixed-model method for association mapping that accounts for multiple levels of relatedness. Nat Genet 38:203-208. https://doi.org/10.1038/ ng 1702

Zampieri M, Ceglar A, Dentener F, Toreti A (2017) Wheat yield loss attributable to heat waves, drought and water excess at the global, national and subnational scales. Environ Res Lett 12:064008. https://doi.org/10.1088/1748-9326/aa723b

Zhang X, Feng H, Feng C et al (2015) Isolation and characterisation of cDNA encoding a wheat heavy metal-associated isoprenylated protein involved in stress responses. Plant Biol 17:1176-1186. https://doi.org/10.1111/plb.12344

Zhao C, Liu B, Piao S et al (2017) Temperature increase reduces global yields of major crops in four independent estimates. Proc Natl Acad Sci USA 114:9326-9331. https://doi.org/10.1073/pnas. 1701762114

Publisher's Note Springer Nature remains neutral with regard to jurisdictional claims in published maps and institutional affiliations. 